\title{
Experimental Performance of Solar Air Heaters for Drying Applications
}

\author{
Gedion Habtay, Maytham A. Al-Neama, Janos Buzas, and Istvan Farkas
}

\section{ABSTRACT}

This paper presents the results of an experimental investigation on an indirect active type of solar dryer, using two distinct solar air collector and their impacts on drying agricultural products. The thermal performance of the proposed collectors has been evaluated using the first and second laws of thermodynamics. Experimental observations were done in climatic conditions Gödöllö, Hungary on the $2^{\text {nd }}$ and $9^{\text {th }}$ of October 2017. The experiments were also carried out to dry $2 \mathrm{~kg}$ of sliced apples spread over the drying trays. The mas flow rate of air was maintained as $0.038 \mathrm{~kg} / \mathrm{s}$ and the dryer was operated from 10:00 a.m. to 3:00 p.m. When a doublepass solar air collector's results are compared to a single-pass solar air collector's, it's evident that the double-pass solar air collector produces much more energy and efficiency. The experimental results showed that singlepass and double-pass collectors have daily efficiencies of $42.77 \%$ and $56.10 \%$, respectively, with average exergy efficiency values ranging from $31 \%$ to $49 \%$ for single-pass and $51 \%$ to $67 \%$ for double-pass. The most significant aspect determining the collectors' thermal efficiency was the temperature rise between the collector outlet and inlet. The average drying efficiencies of the solar dryer for the single and double-pass collectors were evaluated as $12.16 \%$ and $16.45 \%$, respectively. The maximum temperature rise for double-pass was determined to be $20^{\circ} \mathrm{C}$, whereas single-pass was found to be $6.5^{\circ} \mathrm{C}$. Furthermore, the highest drying rate was achieved when sliced apples were dried with a double-pass collector mode. It reduced $52 \%$ of the water content in the apple in the same amount of time as single-pass drying, compared to $35 \%$ in the case of single-pass drying.

Keywords: Apple drying, drying efficiency, energy and exergy analysis, solar air collector.

\section{INTRODUCTION}

Renewable energy sources have become widely used in a variety of applications in the recent century, particularly in the agriculture products drying. Because of its constant availability, solar energy has emerged as the most popular renewable energy source, surpassing wind, and biomass [1]. Simultaneously, quality control and quality preservation innovation become significant advances for handling of agricultural products than before. Solar energy is the promising source of energy for the contribution to lowtemperature $(T<375 \mathrm{~K})$ applications like solar dryer [2], [3]. In general, solar dryers are classified based on air circulation as active solar drying systems (required fans for air circulation) and passive solar drying systems (air circulation due to buoyancy effect). Furthermore, [4] also classified solar dryers based on mode of operation as direct-mode, indirectmode, and mixed-mode dryers.

Active indirect-mode dryer comprises of a solar air heater, opaque drying chamber walls. The purpose of the solar air heater is to convert the radiation from the sun into thermal energy so as increasing the temperature of the air inside the system. Solar air collector is the most important component
Published Online: December 13, 2021

ISSN: $2736-5506$

DOI: $10.24018 /$ ejenergy.2021.1.5.29

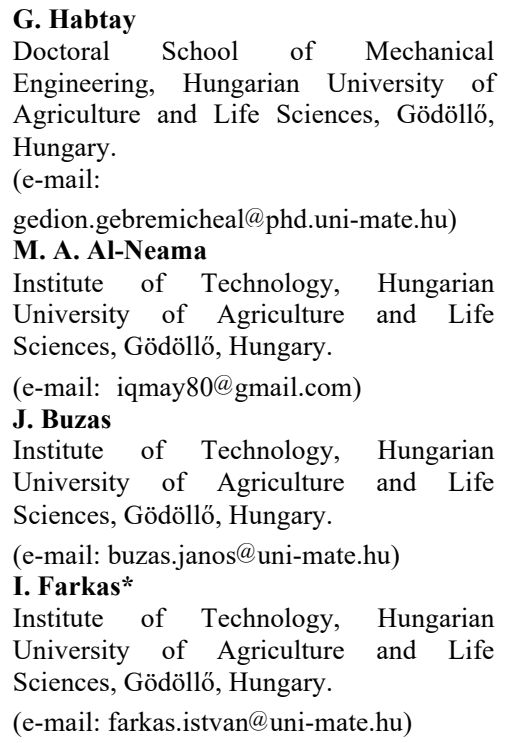

Doctoral School of Mechanical Engineering, Hungarian University of Agriculture and Life Sciences, Gödöllö, Hungary.

(e-mail:

gedion.gebremicheal@phd.uni-mate.hu)

M. A. Al-Neama

Institute of Technology, Hungarian University of Agriculture and Life Sciences, Gödöllő, Hungary.

(e-mail: iqmay80@gmail.com)

J. Buzas

Institute of Technology, Hungarian University of Agriculture and Life Sciences, Gödöllő, Hungary.

(e-mail: buzas.janos@uni-mate.hu)

I. Farkas*

Institute of Technology, Hungarian University of Agriculture and Life Sciences, Gödöllö, Hungary.

(e-mail: farkas.istvan@uni-mate.hu)

*Corresponding Author in the drying process. However, the thermal efficiency of the collector is low due to the low heat transfer coefficient of the air. The heat transfer coefficient of air can be increased if the flow inside the collector is in turbulent flow. Therefore, several researchers have been used different practices on the absorber plate of the collectors in order to develop a turbulent flow so as enhance the thermal efficiency. The baffles integrated and arranged in zigzag manner to the absorber plate was proposed by [5]. The result shows that air temperature is rises due to increase in turbulence flow of the solar air heater. Reference [6] have been using a wire mesh between the fins instead of an absorber plate on double-pass collector. In this study, the result showed that the maximum efficiency and temperature rise obtained when the number fins attached in the absorber plate increased for a fixed mass flow rate. Reference [7] studied experimentally and theoretically on the thermal performance of double-pass using v-corrugated plate. Their results showed that the thermal efficiency of the double-pass air heater with vcorrugated plate is higher than that of a finned double-pass one. Instead using V-corrugated plate, [8] used vertical and horizontal finned plate to evaluate the performance of a double-pass solar air heater experimentally. Changing the 
position of the fins from vertical to horizontal direction, the daily energy efficiency improved by about $10 \%$. Reference [9] evaluated the performance of a mixed-mode solar dryer. They employed artificial rib roughness underside of the absorber plate to enhance the heat transfer coefficient. Other study [10], used porous material to enhance the thermal efficiency of the collector.

Some studies showed that the thermal efficiency of the collector strongly depend on the mass flow rate and solar radiation intensity [11], [12]. In view of optimization of a solar air collector, exergy analysis is a better method for evaluating the performance of the collector because it can evaluate quality of the energy [13], [14].

In this study, the result of an experimental investigation on indirect type solar dryer, using two different solar air collectors, namely a single-pass and a double-pass solar air collector, have been presented. The dryer worked under forced convection with apple slice as used drying product. The energy gain, energy efficiency, exergy gain, exergy efficiency values were calculated with the data obtained from the drying experiments and first and second laws of thermodynamics. System drying efficiency as well as product weight loss also presented in this study.

\section{MATERIAL AND METHODS}

An experimental investigation was carried out on a solar test rig comprises mainly solar air heater, drying chamber and fan where all components have been connected by insulated air ducts. To carry out experimental analysis, two solar air heaters have been constructed namely single-pass solar air collector (SPSAC) and double-pass solar air collector (DPSAC). The schematic views of the constructed collectors were shown in Fig. 1a and $1 \mathrm{~b}$.

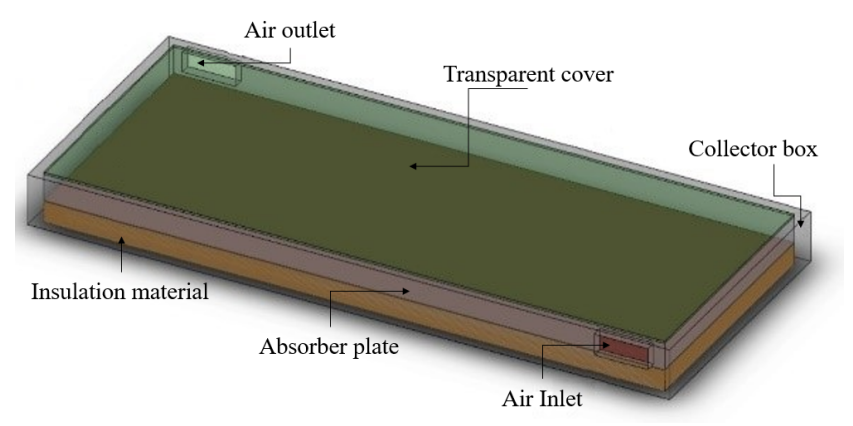

(a)

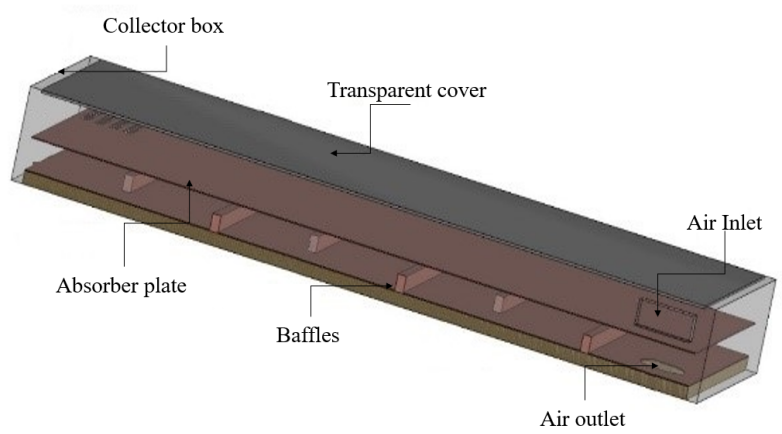

(b)

Fig. 1. Schematic view of solar air collectors: (a) SPSAC; (b) DPSAC.
A $1.2 \mathrm{~mm}$ thick absorber plate was employed to absorb shortwave radiation to enhance the temperature the collector plate. The surface absorptivity of the plate was increased by selectively painting it with enamel paint. A $4 \mathrm{~mm}$ transparent glass (Plexiglass) was used as a collector cover to transmit the high temperature short wave solar radiation to the absorber plate and prevent escaping of long-wavelength radiation to the surrounding. A thermal insulated material (polystyrene) was placed underneath of the absorber plate in order to prevent heat loss from the backside of the collector. The only difference between these collectors is that the second air channel of the double-pass designed in such a way that the buffers are fixed on the back surface of the absorber. These buffers are used as an obstacle to extract maximum amount of heat from the absorber and increases the output temperature of the collector. Air flow occurred over and under the absorber plate having a connection of 25 holes with a diameter of $17 \mathrm{~mm}$. The detailed specifications of these collectors can be found in Table I and II. According to [15], the collectors were oriented true south with a $45^{\circ}$ inclination angle to the horizontal.

TABLE I: COMPONENTS OF SPSAC

\begin{tabular}{cccccc}
\hline \hline Components & $\alpha$ & $\varepsilon$ & $\tau$ & $\lambda$ & Material made \\
\hline \hline Glazing & 0.06 & 0.86 & 0.9 & 0.19 & Plexiglass \\
Absorber & 0.95 & 0.95 & - & 385 & Copper \\
Insulation & - & - & - & 0.04 & Polystyrene \\
Wall & - & - & - & 0.13 & Wood \\
\hline \hline \multicolumn{6}{c}{ TABLE II: COMPONENTS OF DPSAC } \\
\hline \hline Components & $\alpha$ & $\varepsilon$ & $\tau$ & $\lambda$ & Material made \\
\hline \hline Glazing & 0.06 & 0.86 & 0.9 & 0.19 & Plexiglass \\
Absorber & 0.95 & 0.95 & - & 385 & Copper \\
Insulation & - & - & - & 0.04 & Polystyrene \\
Wall & - & - & - & 0.13 & Wood \\
\hline \hline
\end{tabular}

The drying chamber made from $50 \mathrm{~mm}$ thick polystyrene and had overall dimensions $500 \times 500 \times 1000 \mathrm{~mm}$, with five trays. The trays made from plastic nets and fixed with 100 $\mathrm{mm}$ separation between each. The chamber integrated with the solar air heater by a small duct with $100 \mathrm{~mm}$ external diameter (see Fig. 2).

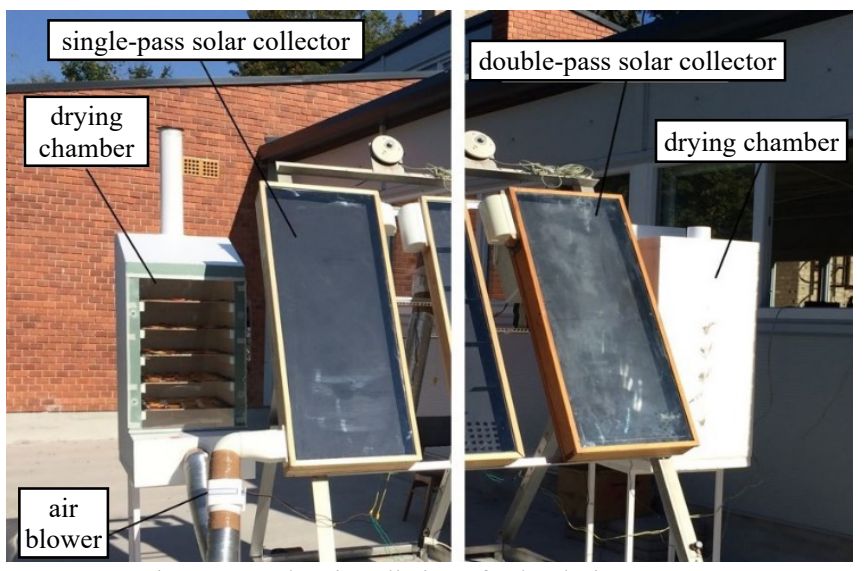

Fig. 2. Complete installation of solar drying system.

The exit heated air from solar heater will enter the drying chamber with high temperature and low moisture content. Energy exchange (heat and mass transfer) occurs between products items and hot air inside the dryer chamber. Then, the 
moist and hot air rises and escapes from the upper vent of drying chamber in case free air movement. The drying chamber's roof was sloped to aid in the smoot circulation of moist air out of the system. In addition, all air leaks from the chamber were sealed as completely as possible.

The experimental study has been conducted at the forecourt of the solar laboratory of Hungarian University of Agriculture and Life Sciences, Gödöllö, Hungary. The geographical latitude and longitude of the site are $47^{\circ}$ $35^{\prime} 39^{\prime \prime} \mathrm{N}, 19^{\circ} 21^{\prime} 59^{\prime \prime} \mathrm{E}$, respectively. The performance of the drying system was continuously observed during $2^{\text {nd }}$ and $9^{\text {th }}$ of experimental days of October 2017, with maximum and minimum ambient air temperatures around $25^{\circ} \mathrm{C}$ and $15^{\circ} \mathrm{C}$, respectively. Solar radiation intensity ranged between $610 \mathrm{~W} / \mathrm{m}^{2}$ and $1066 \mathrm{~W} / \mathrm{m}^{2}$. All the tests were conducted from 10:00 am to 3:00 pm under load condition. The solar radiation intensity was measured with a pyranometer connected to a data logger. The pyranometer measures the voltage generated by the global solar radiation where $5.54 \mathrm{mV}$ is equals to $1 \mathrm{kWm}^{-2}$. The ambient temperature, temperatures in the collectors and drying chamber were measured by using ktype thermocouples. Ambient temperature and relative humidity, inlet, and outlet temperatures of drying air in the collectors and drying chambers were recorded at $10 \mathrm{~min}$ intervals of the drying process to carry out the energy and exergy analyses of the proposed dryers. The velocity of the air at the inlet of the collector is measured by a digital handheld anemometer. All instruments were calibrated before use. The description of equipment utilized during the measurement process is provided in Table III. In this study, a $2000 \mathrm{~g}$ apple was used for drying evaluation. The apples were cut into thin layers and placed uniformly in each tray to achieve maximum drying rate. A digital weight balance was used to quantify weight loss at 2-hour intervals during drying.

TABLE III: INSTRUMENT USED FOR MEASUREMENTS

\begin{tabular}{cccc}
\hline \hline Instruments & Model & Accuracy & Specification \\
\hline \hline Pyranometer & $\begin{array}{c}\text { CM-11, Kipp \& } \\
\text { Zonen }\end{array}$ & $\pm 0.6 \%$ & $\begin{array}{c}\text { Max. } 4000 \\
\mathrm{~W} / \mathrm{m}^{2}\end{array}$ \\
$\begin{array}{c}\text { Data logger for } \\
\text { radiation }\end{array}$ & $\begin{array}{c}\text { ADAM 4018, } \\
\text { Advantech. Co }\end{array}$ & $\pm 0.1 \%$ & $\pm 6 \mu \mathrm{V} /{ }^{\circ} \mathrm{C}$ \\
$\begin{array}{c}\text { Data logger for } \\
\text { temperature }\end{array}$ & $\begin{array}{c}\text { 4CH Temperature } \\
\text { data logger- KRIDA }\end{array}$ & $\pm 0.5{ }^{\circ} \mathrm{C}$ & $-0.5{ }^{\circ} \mathrm{C}$ to \\
Electronics & $125^{\circ} \mathrm{C}$ \\
Thermocouple & $\begin{array}{c}\text { K-Type (Nickel- } \\
\text { Chromium) }\end{array}$ & $\pm 1.1{ }^{\circ} \mathrm{C}$ & $-270{ }^{\circ} \mathrm{C}$ to \\
$1260{ }^{\circ} \mathrm{C}$ \\
Anemometer & $\begin{array}{c}\text { EC-MR 330 } \\
\text { Eurochron GmbH }\end{array}$ & $0.1 \mathrm{~m} / \mathrm{s}$ & $0-30 \mathrm{~m} / \mathrm{s}$ \\
$\begin{array}{c}\text { Digital } \\
\text { Electronic } \\
\text { balance }\end{array}$ & APTP457, & $0.1 \mathrm{~g}$ & $0-5000 \mathrm{~g}$ \\
\hline \hline
\end{tabular}

To investigate the thermal performance of the proposed solar air collectors, first and second laws of thermodynamics had been applied. The thermal performance is evaluated by its efficiency, which is defined based on the first law of thermodynamics as the ratio of the useful energy collected to the total amount of solar radiation hitting the collector's surface over a given period of time [16], [17]. To estimate the useful thermal energy gain $\left(Q_{u}\right)$ by the drying air using the values of the inlet and outlet temperatures of the solar air heater was calculated using (1).

$$
Q_{u}=\dot{m} c_{p}\left(T_{o}-T_{i}\right)
$$

where:

$T_{o}$ and $T_{i}$ : the collector outlet and inlet temperature, respectively.

$c_{p}$ : the specific heat capacity of air at known temperature $(\mathrm{kJ} / \mathrm{kg} \cdot \mathrm{K})$,

$\dot{m}$ : the mass flow rate of air $(\mathrm{kg} / \mathrm{s})$.

Mass flow rate of air can be calculated by multiplying air density, area of air flow duct and air speed:

$$
\dot{m}=\rho V A_{d u c t}
$$

where:

$\rho$ : air density $\left(\mathrm{kg} / \mathrm{m}^{3}\right)$,

$V$ : average air velocity at the collector inlet $(\mathrm{m} / \mathrm{s})$,

$A_{\text {duct: }}$ the cross-section area of the air duct $\left(\mathrm{m}^{2}\right)$.

The total amount of solar radiation hitting the collector's surface over a given period of time:

$$
Q_{I}=I_{T} A_{c}
$$

where:

$I_{T}$ : solar radiation intensity $\left(\mathrm{W} / \mathrm{m}^{2}\right)$,

$A_{c}$ : the absorbing surface area $\left(\mathrm{m}^{2}\right)$.

So, the final form of the collector instantaneous efficiency $\eta_{t h}$ can be as following:

$$
\eta_{t h}=\frac{\dot{m} c_{p}\left(T_{o}-T_{i}\right)}{I_{T} A_{c}}
$$

The net exergy gain based on the $2^{\text {nd }}$ law of thermodynamics is defined as the increase of exergy in the flow of fluid while passing through the solar air collector. With the assumption that air is considered as perfect gas and changes of both the kinetic and potential energy are also neglected in this study, then the exergy gain, $E x_{\mathrm{u}}$ is given by [18].

$$
E x_{u}=\dot{m}\left[c_{p}\left(T_{o}-T_{i}\right)-T_{a}\left(c_{v} \ln \left(\frac{T_{o}}{T_{i}}\right)-R \ln \left(\frac{\rho_{o}}{\rho_{i}}\right)\right)\right] .
$$

Exergy efficiency is also considered as an important parameter to estimate the collector performance. The exergy efficiency can be expressed as the ratio of the absorbed exergy (exergy gain) of air to the exergy of solar radiation on the collector [19].

$$
\eta_{t h}=\frac{E x_{u}}{E x_{i n}}
$$

where: R: is the air gap Rayleigh number (-).

The input exergy of the solar radiation, $E x_{\text {in }}$ is defined as:

$$
E x_{i n}=\left[1+\frac{1}{3}\left(\frac{T a}{T_{S}}\right)^{4}-\frac{4 T_{a}}{3 T_{S}}\right] I_{T} A_{c} \text {, }
$$

where:

$T_{s}$ : temperature of solar intensity and assumed as $5600 \mathrm{~K}$,

$T_{a}$ : temperature of ambient $(\mathrm{K})$,

$c_{v}$ : specific heat capacity of air at constant volume $(\mathrm{J} / \mathrm{kg} \cdot \mathrm{K})$, $\rho_{i}$ and $\rho_{o}$ : density of air at inlet and outlet of the collector $\left(\mathrm{kg} / \mathrm{m}^{3}\right)$. 
Large portion of energy consumed during drying is for transforming water into its vapor from the product. The total energy required to dry any quantity of products can be determined by using the basic energy balance equation for the evaporation of water, as shown in Fig. 3. According to the schematic diagram for the dryer, the basic energy balance equation, can be written as follows:

$$
Q_{a i r, i}+Q_{p r, i}=Q_{a i r, o}+Q_{p r, o}+Q_{L}
$$

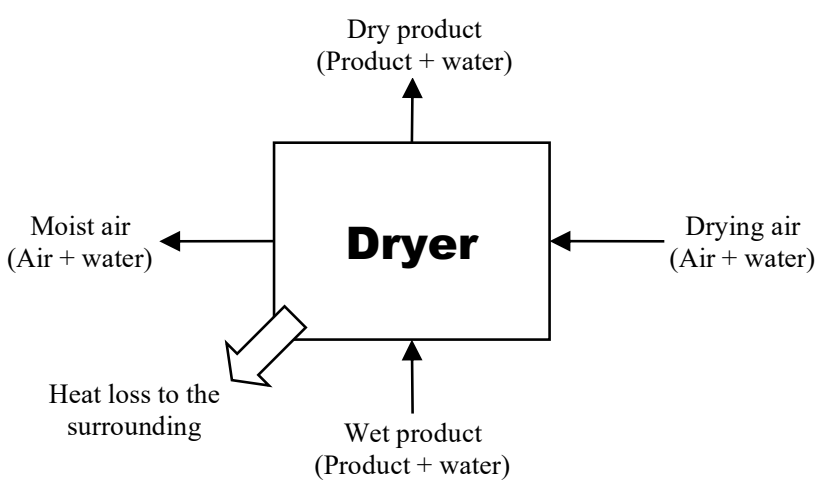

Fig. 3. Energy balance of drying product.

If the drying chamber is well insulated, the energy losses $\left(Q_{L}\right)$ from the dryer can be neglected. (9) was used to calculate the amount of water removed from the product along with the vaporization latent heat $\left(h_{f g}\right)$ :

$$
m_{w} h_{f g}=m_{d} c_{p}\left(T_{d, i}-T_{d, o}\right) .
$$

Assuming there is no heat loss through the connection between the solar heater and dryer. Therefore, the inlet temperature of the drying air can be taken as the outlet temperature of the solar air heater. The amount of water evaporated from the product surface can be determined by (10):

$$
m_{w}=\frac{m_{i}\left(M C_{i}-M C_{f}\right)}{\left(100-M C_{f}\right)}
$$

During drying process, water first evaporates from the surface of the product and then the remaining water from the inner part gradually evaporated. The ability of removal of water from the product depends on the surface area and porosity of the product.

Drying system efficiency $\eta_{\text {sys }}$ of the forced indirect solar dryer is the ratio of the energy required to evaporate water from the product to the heat supplied to the dryer by solar and additional $(E)$ ways. It is a measure of the effectiveness of a drying system and can be expressed mathematically as:

$$
\eta_{s y s}=\frac{m_{w h}{ }_{f g}}{I_{T} A_{C}+E}
$$

where:

$m_{w} h_{f g}$ term is the consumed energy to evaporate water from the product,

$T_{d i}, T_{d o}$ : dry air temperature at inlet and outlet of the drying chamber,

$m_{w}$ : amount of water removed $(\mathrm{kg})$,

$m_{d}$ : amount of drying air $(\mathrm{kg})$, $m_{i}$ : initial weight of the product $(\mathrm{kg})$,

$M C_{i}, M C_{f}$ : initial and final moisture content of the product (\%).

\section{RESUltS AND DISCUSSION}

Experimental studies were carried out in order to evaluate the performance of the solar air collectors for apple drying. Measurements of air velocity, solar irradiance, relative humidity, and the various temperatures were used to calculate the desired characteristic parameters, for example the energy and exergy gain of a solar air collector, efficiency of the system as well as the weight loss of the product. A comparison between the experimental results of the two collectors has been conducted. Air speed of $2.3 \mathrm{~m} / \mathrm{s}$ was selected and placed in a $0.00635 \mathrm{~m}^{2}$ cross-section area of the duct. Wind speed in the days of experiments was low about $1.5 \mathrm{~m} / \mathrm{s}$. The useful heat rate, exergy gain, collector efficiency (energy and exergy efficiency), and drying rate were calculated directly from the data obtained from each collector and drying chamber. All the results of the experiment are presented in the form of graphs that describe solar radiation intensity, temperature rise across the collector, energy and exergy gain, collector efficiency and drying rate of the product as a function of time.

Fig. $4 \mathrm{a}, \mathrm{b}$ shows the variations of the temperatures of the ambient, average absorber plate, inlet and outlet of the solar air collectors with time.

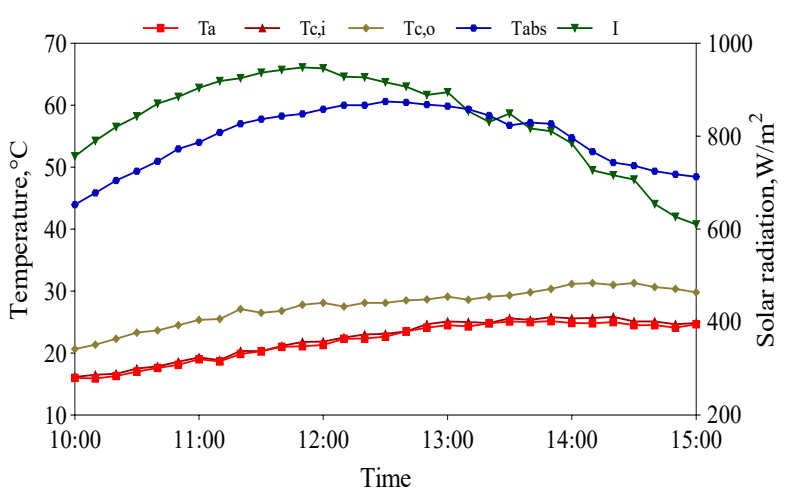

(a)

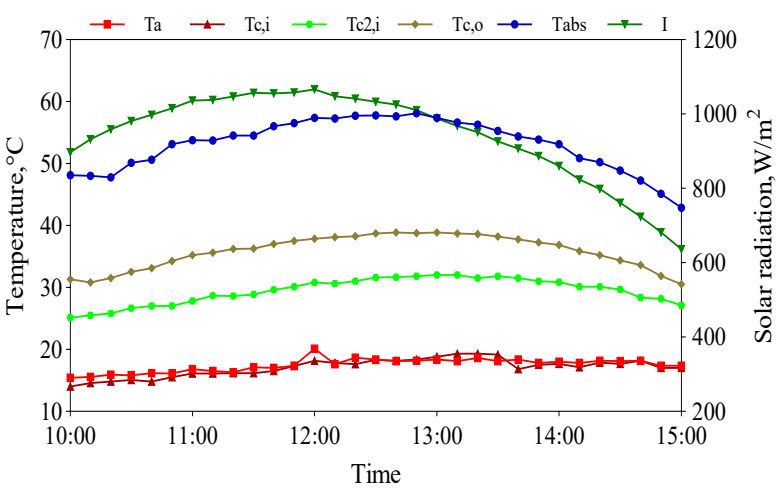

(b)

Fig. 4. Solar radiation and collector temperature (a) SPSAC, (b) DPSAC.

The experimental time period was from 10:00 to 15:00. The maximum temperature attained by the absorber plate was $58.1^{\circ} \mathrm{C}$, which was at $12: 50$. It is useful to know the 
temperatures under different solar radiation conditions as it enables the dryers to be satisfactorily designed. It is observed from the figure that small temperature variation showed between the collector inlet air and ambient temperature. The temperature rises and the solar radiation intensity gradually increased from morning and reaches its maximum at noon and then declined. The highest value of temperature obtained between 12:00 and 13:00, because the highest solar radiation values during this period. The effect of second pass is obvious in the results.

The ambient temperature varied from $15.4{ }^{\circ} \mathrm{C}$ to $25.2{ }^{\circ} \mathrm{C}$ during the study period. It was observed that there was a substantial rise in air temperature in the case of DPSAC. SPSAC tested under conditions little bit warmer than doublepass but the temperature increase with DPSAC was higher. This can be explained that the DPSAC has an increased heat transfer area between air and absorber, and also the air layer in the lower air pass is insulated by the first pass.

Fig. 5 a, b shows the variation of useful heat gains $Q_{u}$ of the solar collectors and the ratio of the change in temperature $(\Delta T)$ to solar radiation $\left({ }^{\circ} \mathrm{C} \mathrm{m}^{2} / \mathrm{W}\right)$ with drying time of the day. The ratio of $\Delta T$ to solar radiation $\left({ }^{\circ} \mathrm{C} \mathrm{m} / \mathrm{W}\right)$ was used as a criterion to compare our results. It can be observed that the maximum value of useful gained heat for SPSAC is $280.8 \mathrm{~W}$, while DPSAC is $362.8 \mathrm{~W}$. This can be explained that the useful heat gain for the DPSAC is the sum of the useful heat gain obtained from upper pass and the lower pass. The variation result of the ratio of $\Delta T$ to solar radiation for SP shows a constant trend while a DP is increasing trend. The fluctuation result of the useful energy of a SP due to the unstable local weather condition for that day. The values of useful heat energy depend mainly on temperature change through the solar collector. Moreover, daily total useful heat for SPSAC is $3985.64 \mathrm{~kW}$, while DPSAC is $5842.47 \mathrm{~kW}$.

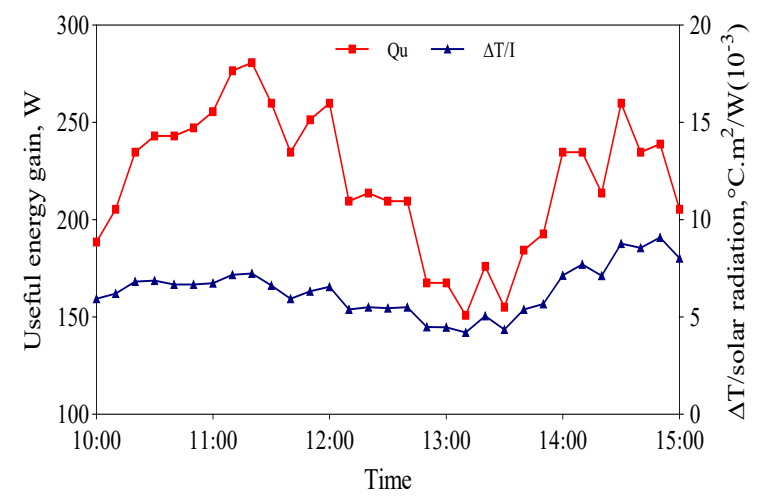

(a)

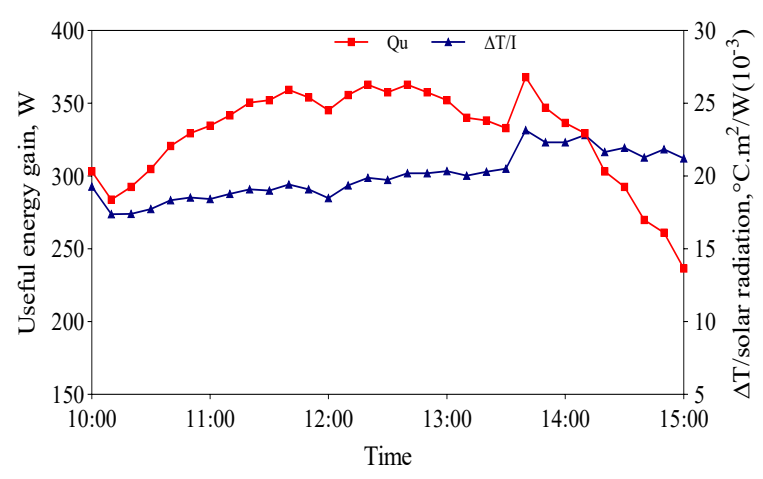

(b)

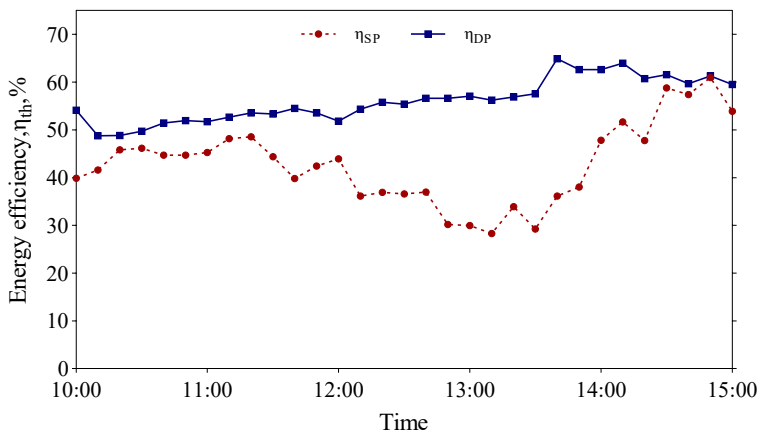

(c)

Fig. 5. (a) Useful energy gain of SPSAC, (b) Useful energy gain of DPSAC, (c) Instantaneous energy efficiency of collector of SPSAC and DPSAC.

The expression of thermal efficiency according (4) depends mainly on gained useful heat from absorbing surface, as a result depends on collector temperature rise. When the absorber plate temperature increases, the amount of useful heat gain is grown. Simultaneously, it will cause more heat losses. Generally, the instantaneous efficiency of the two collectors has very low variation noticed during the variation of climate such as wind speed, ambient temperature and solar radiation intensity. The experimental results showed that daily efficiencies of SP and DP collectors are $42.1 \%$ and $54.8 \%$, respectively. The thermal efficiency is higher by about $30 \%$ with using DPSAC. The improved these collectors are very acceptable compared to cost of solar collector manufacturing. Moreover, their efficiencies have a good agreement with previous studies.

Hourly variation of exergy gains and exergy efficiencies of a SP and DP air collectors has shown in Fig. 6. It is clear, that the exergy gains values gradually increase from 10:00 until around midday and then slowly decrease. These variations are the result of the incident solar radiation increasing till midday and then it begins to decline until sunset. The exergy gains for DP and SP reaches maximum value of about $352 \mathrm{~W}$ and $264 \mathrm{~W}$, respectively.

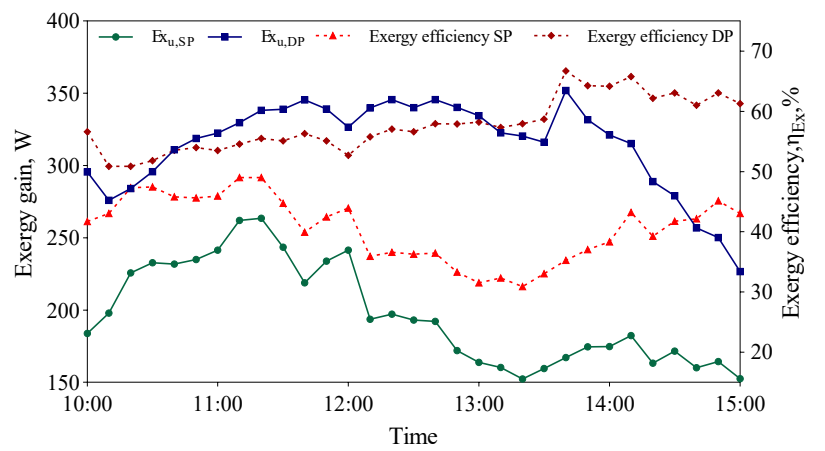

Fig. 6. Comparison of exergy gain and exergy efficiency of SPSAC and DPSAC with time.

It is crucial to calculate the exergy efficiency of the system to understand the performance of these kinds of collectors. The exergy efficiency of the collectors depends on daily solar radiation and the exergy gain. It is increases with increase in exergy energy. The average values of the exergy efficiency vary from $31 \%$ to $49 \%$ in case of SPSAC, whereas it is $51 \%$ to $67 \%$ for the case of DPSAC. As can be seen in this figure, 
the efficiency of the two collectors has an ascending tendency, and only at some intervals there are descending streaks in it. It is due to sudden changes in weather conditions. The exergy efficiency of the DPSAC has maximum value as compared to that of a SPSAC because of the higher heat transfer area and higher temperature rise within the collector. The average temperature rise in DP was higher by about $70 \%$. The maximum temperature rise value for DP has been found to reach a maximum of $20^{\circ} \mathrm{C}$, whereas $6.5^{\circ} \mathrm{C}$ for SP. These values are suggested for drying agricultural products [20].

Fig. $7 \mathrm{a}, \mathrm{b}$ presents the temperatures variation of the five trays inside the drying chamber for SP and DP solar collectors. In this experiment, the solar dryer was loaded with $2 \mathrm{~kg}$ of apple to evaluate its drying behaviour. The apple has been cut into a circular thin layer shape to enhance the drying rate and reduces the drying time [21]. The reason is that the drying rate is affected by the type and size of the product being dried. High temperature is required when the initial moisture content is high. In drying chamber, the temperature of the air inside the chamber decreases, while relative humidity increases. Temperature difference between first and second tray higher than temperature difference between fourth and last tray.

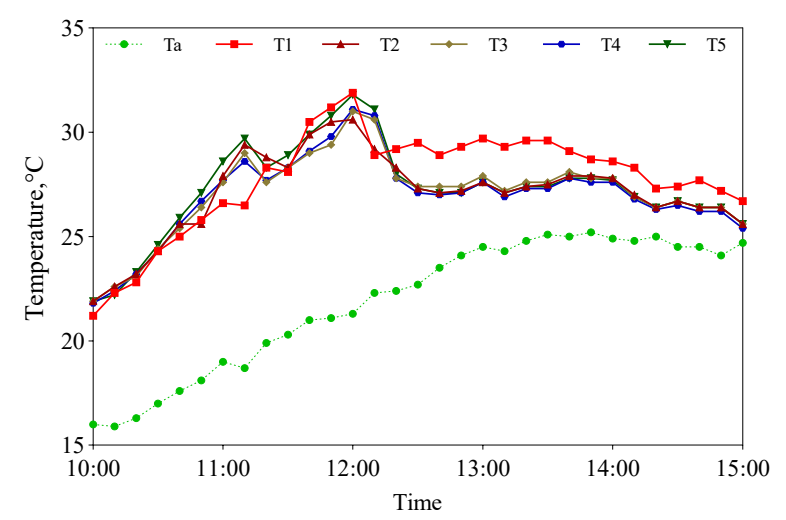

(a)

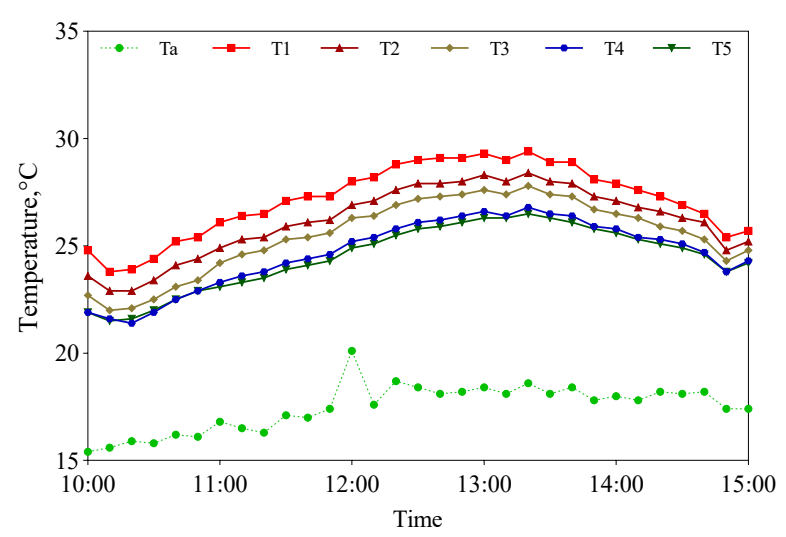

(b)

Fig. 7. Temperature distribution inside drying chamber (a) SPSAC, (b) DPSAC.

The average drying efficiency of the system has determined by using (11) and result is presented in Table IV. The system efficiency is affected by the properties of the dried product i.e., geometry, size, shape, and moisture content, as well as the dry air temperature. In this study, the apples were sliced with a $4 \mathrm{~mm}$ thickness, in order to reduce the drying time. The latent heat of vaporization of water in the product affected by the dry air temperature. Its value reduced with increasing the temperature.

TABLE IV: DEMONSTRATES A COMPARISON BETWEEN THE CURRENT

\begin{tabular}{cccccc}
\multicolumn{5}{c}{ WORK } \\
Type & \multicolumn{2}{c}{ Weight loss, } & \multicolumn{2}{c}{$\begin{array}{c}\text { Average solar air } \\
\text { kg }\end{array}$} & \multicolumn{2}{c}{ collector efficiency, \% } & $\begin{array}{c}\text { Drying } \\
\text { efficiency, \% }\end{array}$ \\
\cline { 2 - 5 } & Initial & Final & Energy & Exergy & \\
\hline \hline SPSAC & 2 & 1.439 & 42.77 & 40.56 & 12.16 \\
DPSAC & 2 & 1.237 & 56.10 & 57.72 & 16.45 \\
\hline \hline
\end{tabular}

Fig. 8 a, b presents the stratification of relative humidity for the same five trays inside drying chamber with using SPSAC and DPSAC as a heat source. In the initial stage of the drying process, due to high moisture content of the product, it is expected that moisture loss from the product is very high. The drying process much faster at the beginning of experiments due to high moisture content in the dried product. Humidity stratification is more noticeable with using DPSAC. After five hours of drying the product weight was measured to find out the final weight for comparison purpose. The results show that the final weights for SP and DP were $1.439 \mathrm{~kg}$ and $1.237 \mathrm{~kg}$, respectively (see in Fig. 9). For SP and DPSAC, the amount of heat energy required to evaporate water from apple product is $0.213 \mathrm{kWh}$ and $0.475 \mathrm{kWh}$, respectively. When employing a DPSAC for a particular drying time, $52 \%$ of the water evaporated, compared to $35 \%$ when using a SPSAC. The constant drying rate of apple was observed due to the fact, that its original moisture content was very high.

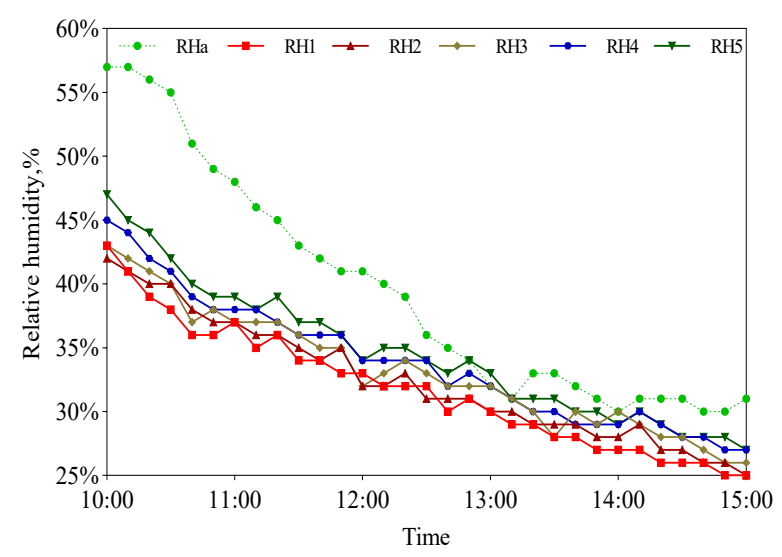

(a)

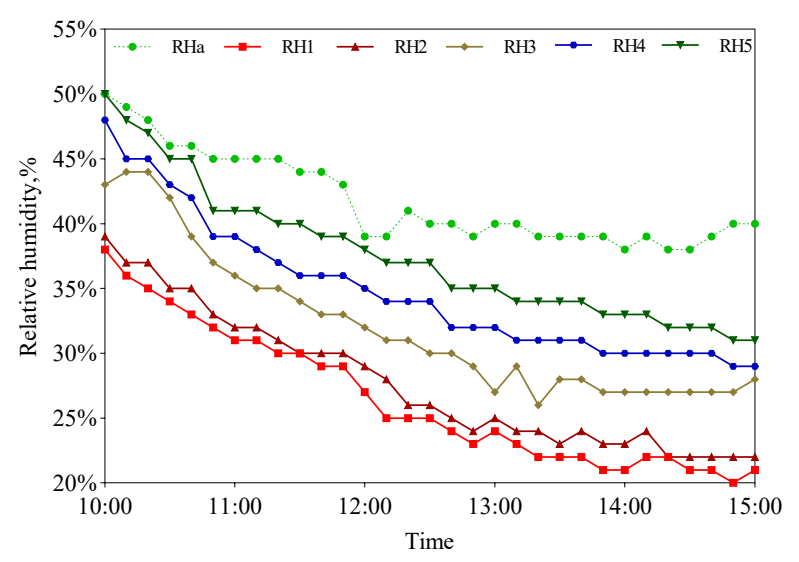

(b)

Fig. 8. Relative humidity of dry air inside drying chamber for the five trays, (a) SPSAC, (b) DPSAC. 


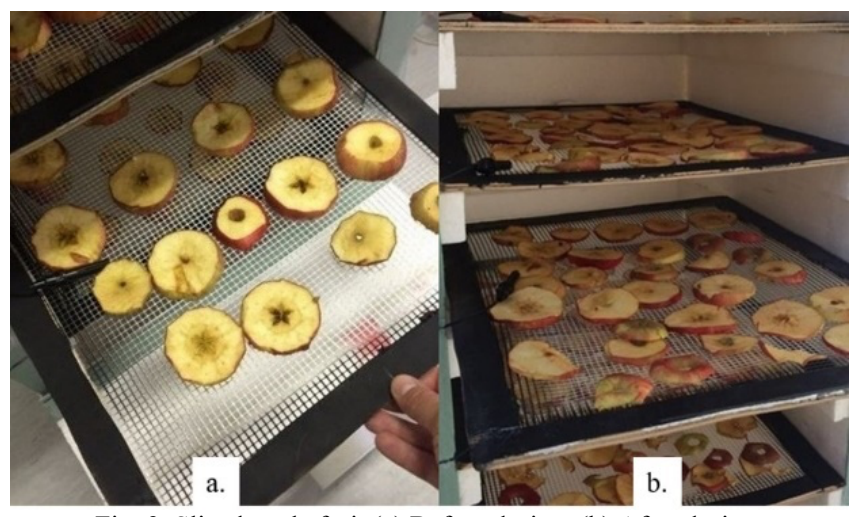

Fig. 9. Sliced apple fruit (a) Before drying, (b) After drying.

\section{CONCLUSION}

Two solar air collectors with drying chambers under forced convective were designed and tested experimentally based on Gödöllö weather conditions. In this study, energy and exergy analysis, and drying efficiency, were employed to compare the two types of solar air collectors for drying apples. The double-pass solar collector has a $29 \%$ greater useful energy gain and 30\% higher energy efficiency than the single-pass. With an average of $88 \mathrm{~W}$ and 19\% efficiency, the collector with double-pass offers a higher value in terms of exergy gain and exergy efficiency. As the exergy gain is increased, the collector's exergetic efficiency improves. The daily solar radiation incident has a significant impact on the energy efficiency. Furthermore, the system with double-pass collector has a higher drying efficiency than one with a single-pass collector. The final weight of the dried product is $1.237 \mathrm{~kg}$ with a double-pass solar collector and $1.439 \mathrm{~kg}$ with a single-pass collector after five hours of drying. The production costs, time, and materials for both collectors are nearly identical. Based on the findings of this investigation, double-pass collectors are superior to single-pass collectors.

\section{ACKNOWLEDGMENT}

This work was supported by the Stipendium Hungaricum Program and by the Doctoral School of Mechanical Engineering, Hungarian University of Agriculture and Life Sciences, Gödöllö, Hungary.

\section{CONFLICT OF INTEREST}

Authors declare that they do not have any conflict of interest.

\section{REFERENCES}

[1] Gunasekaran N, Kumar PM, Raja S, Sharavanan S, Avinas K, Kannan PA, Gokul S. Investigation on ETC solar water heater using twisted tape inserts. Materials Today: Proceedings, vol. 47, Part 15, pp. 50115016, 2021. doi: 10.1016/j.matpr.2021.04.586

[2] Fudholi A, Sopian K, Ruslan MH, Alghoul MA, Sulaiman MY. Review of solar dryers for agricultural and marine products. Renew Sustain Energy Rev. 2010 Jan;14(1):1-30.

[3] Ajam H, Farahat S, Sarhaddi F. Exergetic optimization of solar air heaters and comparison with energy analysis. International Journal of Thermodynamics. 2005 Dec;8(4):183-190.
[4] Afriyie JK, Nazha MAA, Rajakaruna H, Forson FK. Experimental investigations of a chimney-dependent solar crop dryer. Renew Energy. 2009 Jan;34(1):217-222.

[5] Halewadimath SS, Subbhapurmath P, Havaldar N, Hunashikatti K, Gokhale S, Experimental analysis of solar air dryer for agricultural products. International Research Journal of Engineering and Technology. 2015 Jun;2(3):1517-1523.

[6] El-Khawajah MF, Aldabbagh LBY, Egelioglu F. The effect of using transverse fins on a double pass flow solar air heater using wire mesh as an absorber. Sol Energy. 2011 Jul;85(7):1479-1487.

[7] El-Sebaii AA, Aboul-Enein S, Ramadan MRI, Shalaby SM, Moharram BM. Thermal performance investigation of double pass-finned plate solar air heater. Appl Energy. 2011 May;88(5):1727-1739.

[8] Al-Neama MA, Farkas I. Thermal efficiency of vertical and horizontalfinned solar collector integrated with forced air circulation dryer for apple as a sample. Dry Technol. 2019 Apr;37(5):546-558.

[9] Pardhi CB, Bhagoria J.L. Development and performance evaluation of mixed-mode solar dryer with forced convection. International Journal of Energy and Environmental Engineering. 2013 Dec;4(1):1-8.

[10] Ramani BM, Gupta A, Kumar R. Performance of a double pass solar air collector. Sol Energy. 2010 Nov;84(11):1929-1937.

[11] Akpinar EK, Koçyiğit F. Energy and exergy analysis of a new flat-plate solar air heater having different obstacles on absorber plates. Appl Energy. 2010 Nov;87(11):3438-3450.

[12] Yousef AAB, Adam NM. Performance and cost analysis of double duct solar air heater. Int J Sci Technol Res. 2012 Jul;1(6):108-116.

[13] Saidur R, BoroumandJazi G, Mekhlif S, Jameel M. Exergy analysis of solar energy applications. Renew Sustain Energy Rev. 2012 Jan;16(1):350-356.

[14] Ahmadi MH, Nazari MA, Sadeghzadeh M, Pourfayaz F, Ghazvini M, Ming T, et al. Thermodynamic and economic analysis of performance evaluation of all the thermal power plants: A review. Energy Sci Eng. 2019 Feb;7(1):30-65.

[15] Duffie J, Beckman W. Solar engineering of thermal processes. 4th ed. New Jersey: John Wiley \& Sons; 2013, ch.1, pp. 12-13.

[16] Kurtbas I, Durmuş A. Efficiency and exergy analysis of a new solar air heater. Renew Energy. 2004 Jul;29(9):1489-1501.

[17] Esen H. Experimental energy and exergy analysis of a double-flow solar air heater having different obstacles on absorber plates. Build Environ. 2008 Jun;43(6):1046-1054.

[18] Bahrehmand D, Ameri M, Gholampour M. Energy and exergy analysis of different solar air collector systems with forced convection. Renew Energy. 2015 Nov;83:1119-1130.

[19] Singh S, Agrawal S, Avasthi DV. Optimization of design parameters of glazed hybrid photovoltaic thermal module using genetic algorithm. 2014 Innovative Applications of Computational Intelligence on Power, Energy and Controls with their impact on Humanity (CIPECH), 2014, pp. 405-410, doi: 10.1109/CIPECH.2014.7019059.

[20] Prasad K, Mullick SC. Heat transfer characteristics of a solar air heater used for drying purposes. Appl Energy. 1983 Feb;13(2):83-93.

[21] Doymaz I, Özdemir Ö. Effect of air temperature, slice thickness and pretreatment on drying and rehydration of tomato. Int J Food Sci Technol. 2014 Feb;49(2):558-564. 